\title{
PENGARUH KELEBIHAN BERAT BADAN / OVERWEIGHT TERHADAP TERJADINYA DISFUNGSI SEKSUAL PRIA
}

\author{
${ }^{1}$ Annisa Husain \\ ${ }^{2}$ Lydia Tendean \\ ${ }^{2}$ Edwin de Queljoe \\ ${ }^{1}$ Kandidat Skripsi Fakultas Kedokteran Universitas Sam Ramtulangi \\ ${ }^{2}$ Bagian Biologi Universitas Sam Ratulangi \\ Email: ahusain11_198@yahoo.com
}

\begin{abstract}
Overweight takes place due to non-proportional between consumed foods and physical activities. In developing countries, about $60 \%$ or about 10.6 million men in Asian countries suffered from overweight. Overweight may disturb sexual performance, which is erectile dis-function. The objective of this study is to determine the relationship between overweight and erectile dis-function. This study is classified as descriptive observational research. It has been conducted in Malalayang Bus Terminal Manado. Thirty (30) respondents, which are city transportation (mikrolet) drivers suffered from overweight, have been interviewed using questionnaire employing IIEF-5 (International Index of Erectile Function)questionnaire. The study reveals that the erectile function among 30 respondents, 21 respondents (70\%) are categorized as normal, 4 respondents (13\%) are slightly disturbed, and 5 respondents (17\%) are slightly to moderate. It can be concluded that overweight influences men erectile function.
\end{abstract}

Keywords: erectile dis-function and overweight.

\begin{abstract}
Abstrak: Overweight merupakan suatu permasalahn yang mendunia. Di negara berkembang, jumlah pria dengan overweight terbanyak berada di kawasan Asia yaitu 60\% populasi atau sekitar 10,6 juta jiwa. Overweight dapat dipengaruhi oleh beberapa faktor, salah satunya adalah faktor lingkungan, termasuk didalamnya masalah dalam pemilihan jenis makanan, pola makan, porsi perkali makan dan tingkat aktivitas pada masing-masing individu. Kelebihan berat badan / overweight dapat menggangu kehidupan seksual pria dalam hal ini disfungsi ereksi. Tujuan penelitian ini adalah untuk mengetahui hubungan antara kelebihan berat badan / overweight dengan disfungsi ereksi. Penelitian dilakukan di Terminal Malalayang, Kecamatan Malalayang, Kota Manado, dengan jumlah sampel 30 orang. Penelitian ini merupakan jenis penelitian obsevasional deskriptif. Fungsi ereksi dapat dinilai dengan menggunakan kuesioner IIEF-5 (International Index of Erectile Function). Penelitian ini menunjukkan bahwa dari 30 pria overweight terdapat 21 orang $(70 \%)$ normal, 4 orang $(13 \%)$ denagn disfungsi ereksi ringan, dan 5 orang (17\%) dengan disfungsi ereksi ringan-sedang. Dari hasil penelitian ini dapat disimpulkan bahwa overweight memiliki pengaruh terhadap terjadinya disfungsi ereksi pria.
\end{abstract}

Kata kunci: disfungsi ereksi, overweight

Kelebihan berat badan atau Overweight adalah kondisi berat badan seseorang yang melebihi berat badan normal yang pada umumnya dapat berasal dari berat otot, tulang, lemak, dan atau air. ${ }^{1}$ Di negara berkembang, jumlah pria dengan overweight terbanyak berada di kawasan Asia yaitu $60 \%$ populasi atau sekitar 10,6 juta jiwa. Menurut penelitian Ito \& Murata (1999), di Jepang prevalensi overweight 
berkisar antara 5\% s/d 11\%. ${ }^{1}$ Prevalensi overweight di Indonesia dalam beberapa dekade terakhir cenderung mengalami peningkatan. Menurut Riset Kesehatan Dasar (RISKESDAS) tahun 2010 prevalensi nasional overweight dan obesitas pada penduduk kelompok umur diatas 18 tahun adalah 21,9\%.

Overweight dapat dipengaruhi oleh beberapa faktor, salah satunya adalah faktor lingkungan, termasuk didalamnya masalah dalam pemilihan jenis makanan, pola makan, porsi perkali makan dan tingkat aktivitas pada masing-masing individu.

Banyak teknik yang digunakan untuk menentukan akumulasi lemak yang ada di dalam tubuh seseorang. Salah satunya adalah dengan mengukur dan menghubungkan berat badan dengan tinggi badan menggunakan Body Mass Index (BMI) / Indeks Massa Tubuh (IMT). ${ }^{2}$

Overweight dapat mengganggu kehidupan seksual pria dalam hal ini disfungsi ereksi. Penelitian yang dilakukan di Eropa membahas tentang kerusakan fisik dan fungsi seksial pria yang mengalami overweight, didapatkan data bahwa pria dengan BMI $>23 \mathrm{~kg} / \mathrm{m}^{2}$ memiliki kemungkinan lebih besar untuk memperlihatkan dua atau lebih gejala yang mengarah pada kerusakan fisik dan gangguan fungsi seksual. Overweight bisa disebabkan oleh penimbunan lemak tubuh, dimana kelebihan lemak tubuh dapat meningkatkan kadar esterogen, yang selanjutnya dapat mengurangi kadar testosteron. ${ }^{3}$

Yang dimaksud dengan disfungsi ereksi adalah ketidakmampuan berulang pada pria dalam mencapai dan mempertahankan ereksi yang cukup untuk melakukan hubungan seksual, yang terjadi selama minimal 3 bulan. Berdasarkan uraian tersebut, dapat diketahui bahwa fungsi seksual seorang pria bisa dipengaruhi oleh gaya hidup pria tersebut. Dengan gaya hidup yang tidak sehat seperti pola makan yang tidak teratur dan berlebihan, serta olahraga yang kurang, bisa menyebabkan kelebihan berat badan pada seorang pria, dimana kelebihan berat badan dapat mengganggu fungsi seksual pada pria.

Dari latar belakang diatas, maka peneliti merasa tertarik untuk melakukan penelitian tentang “ Pengaruh Kelebihan Berat Badan/Overweight terhadap Disfungsi Ereksi “.

\section{METODE PENELITIAN}

Desain penelitian yang digunakan merupakan penelitian deskriptif. Penelitian dilakukan di Terminal Malalayang. Manado, Sulawesi Utara dalam rentang waktu dari bulan November 2014 sampai Desember 2014. Sampel yang digunakan berjumlah 30 orang, dengan tehnik pengambilan sampel Purposive Random Sampling dan ditetapkan berdasarkan kriteria inklusi dan eksklusi. Adapun kriteria inklusinya yaitu pria overweight dengan IMT $>23,0-24,9 \mathrm{~kg} / \mathrm{m}^{2}$, usia 30 45 tahun, dan telah menikah, sedangkan yang termasuk dalam kriteria eksklusi yakni pria yang memiliki riwayat penyakit, IMT $<23,0 \&>24,9 \mathrm{~kg} / \mathrm{m}^{2}$, belum menikah, responden menolak, serta usia < 30 tahun \& > 45 tahun. Variabel yang diteliti dalam penelitian ini yaitu Overweight sebagai veriabel bebas dan disfungsi ereksi sebagai variable terikat. Data primer untuk variable bebas didapatkan melalui pengukuran tinggi dan berat badan untuk memperoleh nilai indeks masa tubuh masing-masing responden, sedangkan data primer untuk variable terikat didapatkan melalui hasil pengisian kuesioner IIEF. Analisis data yang digunakan adalah analisis univariat dan bivariat.

\section{HASIL PENELITIAN DAN BAHASAN}

Seluruh sampel telah memenuhi kriteria inklusi penelitian. Pada penelitian ini didapatkan jumlah sampel 30 orang, dan dibagi berdasarkan kategori usia 30-35 tahun sebanyak 14 orang, 36-40 tahun sebanyak 14 orang, 41-45 tahun 2 orang. Setelah dilakukan penelitian dengan pembagian kuesioner baku IIEF-5 yang telah dimodifikasi menjadi 6 (Indeks 
Internasional Ereksi) didapatkan kesimpulan hasil mengenai fungsi ereksi pada pria yang mengalami kelebihan berat badan loverweright. Secara keseluruhan penelitian yang dlakukan pada pria dengan overweight yang berpengaruh terhadap disfungsi ereksi didapatkan beberapa responden mengalami disfungsi ereksi dan dengan tingkatan atau stadium yang berbeda-beda yang dijabarkan pada tabel dibawah, didapatkan distribusi overweight berdasarkan kelompok usia yaitu, Normal sebanyak 21 orang (70\%), Disfungsi ereksi ringan sebanyak 4 orang (13\%), Disfungsi ereksi sedang-ringan 5 orang (17\%), disfungsi sedang 0 orang, dan disfungsi berat 0 orang.

Distribusi Overweight menurut hasil perhitungan skor IIEF berdasarkan kelompok usia.

\begin{tabular}{llllll}
\hline & \multicolumn{2}{l}{ USIA } & \multicolumn{3}{l}{ RESPOND } \\
FUNGSI & \multicolumn{2}{l}{ (TAHUN) } & \multicolumn{2}{c}{ EN } \\
\cline { 2 - 6 } EREKSI & $\mathbf{3 0 -}$ & $\mathbf{3 6 -}$ & $\mathbf{4 1 -}$ & $\mathbf{N}$ & $\mathbf{\%}$ \\
& $\mathbf{3 5}$ & $\mathbf{4 0}$ & $\mathbf{4 5}$ & & \\
\hline Normal & 9 & 10 & 2 & 21 & 70 \\
DE & 2 & 1 & 1 & 4 & 13 \\
$\begin{array}{l}\text { Ringan } \\
\text { DE }\end{array}$ & 3 & 2 & 0 & 5 & 17 \\
$\begin{array}{l}\text { Sedang- } \\
\text { ringan }\end{array}$ & & & & & \\
$\begin{array}{l}\text { DE } \\
\text { Sedang }\end{array}$ & 0 & 0 & 0 & 0 & 0 \\
DE Berat & 0 & 0 & 0 & 0 & 0 \\
\hline Total & $\mathbf{1 4}$ & $\mathbf{1 3}$ & $\mathbf{3}$ & $\mathbf{3 0}$ & $\mathbf{1 0 0}$ \\
\hline
\end{tabular}

Pada Tabel berikut ini didapatkan distribusi overweight menurut kategori Disfungsi Ereksi berdasarkan Indeks Massa Tubuh (IMT) yaitu pada IMT 23-23.5 tidak terdapat pria dengan Disfungsi ereksi, pada IMT 23,6-24 tidak terdapat pria dengan disfungsi ereksi, dan pada IMT 24,1 - 24,9 terdapat 9 orang dengan disfungsi ereksi ringan. Pada tabel diatas dapat dilihat bahwa semakin tinggi nilai IMT, jumlah responden dengan fungsi seksual normal semakin berkurang.Hal ini didukung oleh penelitian yang dilakukan oleh The Health Professionals Follow-up
Study pada 22.086 pria di Amerika yang memperlihatkan hubungan jelas antara overweight dengan salah satu komponen disfungsi seksual yakni disfungsi ereksi. Diketahui bahwa obesitas berhubungan dengan rendahnya kadar hormon testosteron dan penurunan kadar sex hormone binding globulin (SHBG) yang berperan dalam fungsi seksual hal ini disfungsi ereksi lebih banyak terjadi pada pria dengan overweight dan obesitas. ${ }^{4}$

Disfungsi seksual pada pria yang mengalami overweight dipicu oleh rendahnya kadar hormon testosteron total,testosteron bebas dan SHBG (Sex Hormone Binding Globulin) yang mereka miliki. Hal ini disebabkan karena adanya peningkatan kadar estrogen, sebagai hasil dari aromatisasi androgen di bagian perifer jaringan adiposa penderita obesitas. Dengan adanya perubahan kadar hormon tersebut maka akan terjadi penekanan pada jalur hipotalamus hipofisis yang mengakibatkan adanya umpan balik negatif terhadap produksi hormon testosteron yang berperan dalam disfungsi ereksi pada pria. ${ }^{5}$

Berdasarkan mekanisme yang telah diuraikan diatas maka dapat dilihat bahwa pria dengan overweight memiliki resiko lebih tinggi untuk mengalami disfungsi ereksi.

Distribusi overweight menurut kategori Disfungsi Ereksi berdasarkan Indeks Massa Tubuh (IMT)

\begin{tabular}{lll}
\hline \multirow{2}{*}{ IMT } & \multicolumn{2}{l}{ DISFUNGSI EREKSI } \\
& YA & TIDAK \\
\hline $23-23,5$ & 0 & 8 \\
$23,6-24$ & 0 & 13 \\
$24,1-24,9$ & 9 & 0 \\
\hline TOTAL & $\mathbf{9}$ & $\mathbf{2 1}$ \\
\hline
\end{tabular}

\section{SIMPULAN}

Hasil penelitian ini disimpulkan bahwa overweight memiliki pengaruh terhadap terjadinya disfungsi ereksi pria.. Dimana semakin tinggi nilai IMT pria, akan semakin tinggi pula resiko terjadinya disfungsi ereksi. 


\section{SARAN}

1. Perlu dilakukan penelitian dengan jumlah sampel yang lebih banyak dan prosedur penelitian yang lebih lengkap, agar didapatkan data dengan cakupan populasi lebih besar dan data yang lebih lengkap.

2. Perlu dilakukan penelitian lanjutan dengan pemeriksaan awal yang lebih lengkap sehingga faktor lain yang menyebabkan disfungsi ereksi pada pria dapat dikendalikan.

\section{DAFTAR PUSTAKA}

1. Caballero, B. 2007. "World Health Organisation. Controlling the global obesity epidemic". Johns Hopkins Bloomberg School of Public Health. vol 29:1-5
2. Obesity: Preventing and Managing The Global Epidemic. WHO Technical Report, Series 2000: 894,

3. Hadi, Hamam. Beban ganda masalah gizi dan implikasinya terhadap kebijakan pembangunan kesehatan nasional. 2005.

:http://gizi.depkes.go.id/wpcontent/up load/2012/05/Beban-ganda-masalahgizi.pdf (di akses 12 desember 2014)

4. Corona G, Vita de G, Sforza A, Maggi M.Obesity and Erectile Dysfunction. European Urological Review. Italy. 2009

5. Hiola Zuriaty. 2010 "Pengaruh Obesitas Terhadap Disfungsi Seksual Pria”. Skripsi . Manado : Fakultas Kedokteran Unsiversitas Sam Ratulangi. 